Archives de sciences sociales des religions

130 | avril - juin 2005

Les Saints et les Anges...

\title{
Les Saints et les Anges...
}

\section{André Mary}

\section{OpenEdition}

Journals

Édition électronique

URL : http://journals.openedition.org/assr/1204

DOI : $10.4000 /$ assr. 1204

ISSN : $1777-5825$

Éditeur

Éditions de l'EHESS

\section{Édition imprimée}

Date de publication : 1 avril 2005

Pagination : 9-11

ISBN : 2-7132-2044-0

ISSN : 0335-5985

Référence électronique

André Mary, "Les Saints et les Anges... », Archives de sciences sociales des religions [En ligne], 130 | avril - juin 2005, mis en ligne le 10 novembre 2005, consulté le 19 avril 2019. URL : http:// journals.openedition.org/assr/1204; DOI : 10.4000/assr.1204

Ce document a été généré automatiquement le 19 avril 2019

(c) Archives de sciences sociales des religions 


\title{
Les Saints et les Anges...
}

\author{
André Mary
}

1 Ce dossier de varia n'a pas les prétentions d'un numéro thématique savamment préparé. Venus d'Argentine, de Russie, d'Inde, du Moyen-Orient, et de France, ces articles se sont ordonnés d'eux-mêmes autour du thème des Saints et des Anges, auxquels sont associés les Héros et les Martyrs. Tous les anges ne sont pas des saints, tous les morts éminents ne sont pas voués à être des saints hommes, et tous les héros ou les saints ne sont pas des martyrs. La plasticité et la multiplicité de ces êtres extra-ordinaires, construits à la frontière du monde des dieux et des hommes, du sacré et du politique, de la mystique et de la guérison, permettent néanmoins de comprendre les vertus de médiation et d'intercession, qui en font, plus que jamais, des acteurs de la modernité religieuse.

2 La typologie des anges, comme la topographie des saints, offre aux besoins d'identification des individus les ressources d'imaginaire qui alimentent un bricolage privé ou familial de toute sorte de dispositifs cultuels, même si la régulation institutionnelle s'exerce aussi sur ces marges et ces espaces alternatifs. Les figures revisitées des saints, héros et martyrs, sont aussi au fondement de l'invention moderne de nouvelles traditions locales, et servent de relais à une culture de pèlerinage urbaine et contemporaine qui traduit aussi bien les affirmations identitaires des groupes ethniques ou nationaux que les contradictions de l'impératif de l'individualité.

3 Les anges de la littérature ésotérique dont nous parle A. Manevy ne sont pas les saints anges, archanges ou bons anges, « canonisés » par la tradition catholique, ni les " génies » d'un monde païen réhabilité par le monde moderne; ils s'inscrivent dans la continuité des ressources psychologiques et morales qu'incarnaient les « anges gardiens » mais en opérant un déplacement significatif. La typologie des anges nommés et individualisés fonctionne dans le monde haziélien comme une caractérologie au service du souci de soi et de l'accomplissement personnel. Si l'on peut parler d'un «bricolage » ésotérique de traditions hétérogènes (catholiques, hébraïques), ce droit revendiqué au mélange n'est pas sans contrainte: la conscience morale que représentait l'ange gardien fait place à l'impératif de la réalisation de soi et aux nouvelles normes de compétence et de performance de l'individu. La logique du cumul appliqué aux ressources de la médication savante et de la guérison miraculeuse est aussi au cœur de l'évolution du culte argentin 
de Saint Pantaléon que nous décrit C. Laigneau. Confronté à la concurrence des Églises pentecôtistes et au défi des groupes charismatiques, le catholicisme argentin, comme bien d'autres, est conduit à redonner vie, à la marge, aux réponses que les sanctuaires et les saints guérisseurs apportent aux attentes privées et individuelles des fidèles souffrants. L'enjeu reste néanmoins le contrôle institutionnel des charismes qui passe par le monopole clérical de l'imposition des mains et la bénédiction de l'onction.

4 A. A. Paněnko met toute sa compétence reconnue d'ethnologue des pratiques religieuses des campagnes de Russie pour nous montrer, à propos du culte rendu à deux « enfantssaints " guérisseurs, que l'individualisation de longue date des formes de dévotion populaire, - leur repli sur la vie privée et familiale-, n'est pas incompatible avec la persistance d'une matrice culturelle paysanne, comme l'illustrent les structures narratives des récits d'enfants martyrs et thaumaturges et leur extraordinaire diffusion. Les malentendus surgissent avec la demande croissante de pèlerinage de populations urbaines confinées, sous le régime de l'athéisme d'État, à une forme de religiosité latente ou invisible. Là encore le clergé local s'efforce de gérer une "religion pèlerine » plus soucieuse de l'investissement des ressources rituelles et thérapeutiques des lieux saints des campagnes que des enjeux de la " mémoire collective » paysanne.

5 Les pratiques de prière que nous présente $\mathrm{H}$. Basu s'inscrivent dans un tout autre contexte, celui d'une région du nord-ouest de l'Inde (Kacch), où ces chants poétiques de louange étaient traditionnellement la spécialité d'une caste de «bardes » qui rendaient ainsi rituellement hommage dans la cour royale à leur maître et héros légendaire (roi chasseur ou guerrier). Après la dissolution de la royauté Rajput et la perte de pouvoir social de la caste dans la période coloniale et postcoloniale, le même habitus de caste contribue à la redéfinition identitaire d'une nouvelle communauté de mémoire et de sentiment. Mais le déplacement est là aussi significatif : le culte des héros royaux laisse place à la dévotion et aux louanges de " déesses humaines », figures historiques porteuses des valeurs ascétiques d'un réformisme social contemporain, et médiums dispensateurs des dons qui offrent les ressources de l'accomplissement individuel autant que de l'affirmation identitaire.

6 La note critique de Malika Zeghal sur les saints, héros et martyrs du monde musulman vient à point nommé pour ouvrir sur d'autres enjeux identitaires plus radicalement politiques et religieux abordés par quelques ouvrages récents (C. Mayeur-Jaouen, F. Khosrokhavar). La plasticité et la circularité de ces figures d'identification collective ou individuelle ne prennent tout leur sens que par les contraintes qui pèsent sur le jeu des écarts et des transformations possibles au sein de cette typologie triangulaire, au dessus de laquelle plane la figure du prophète. Le culte de la personne qui entoure les chefs d'État du monde arabe conduit à en faire des héros nationaux mais pas automatiquement des saints ou des martyrs, et les relais qu'offre le sacré par rapport au politique restent ambigus. Enfin comme l'illustrent les figures récentes des martyrs médiatiques ou virtuels, les figures du saint ou du martyr ne franchissent pas impunément les frontières et ne s'exportent pas dans n'importe quel contexte. En passant des cultes locaux aux espaces nationaux, et encore plus aux réseaux transnationaux, les vertus d'identification ou d'intercession qu'on leur prête tendent à s'épuiser ou même à se retourner. Entre le réel et le virtuel, l'imaginaire des anges rejoint celui des démons. 